\title{
Recensión del libro: Recensión del libro Social Entrepreneurship and Innovation de Ken Banks
}

\author{
Carlos Sandoval Álvarez* \\ * Universidad de Costa Rica, Costa Rica. Contacto: c.sandoval@gmx.de
}

Referencia/ reference:

Sandoval, C (2019). Recensión del libro Social Entrepreneurship and Innovation de Ken Banks. Yulök. Revista de Innovación Académica, 4 (1), 101-102

Los problemas más desafiantes del mundo están siendo asumidos por personas motivadas por su pasión personal, informadas por la comprensión profunda de las realidades locales y moldeadas por su frustración por las soluciones estatales inadecuadas ante los problemas. La obra "Social Entrepreneurship and Innovation" (2016) de Ken Banks nos introduce al mundo del emprendimiento social e innovación social desde una perspectiva vivencial, a través de casos reales de innovación que han transformado radical y exitosamente pueblos y sociedades. Los casos que presenta dicha obra son de diversos temas, realidades y latitudes,

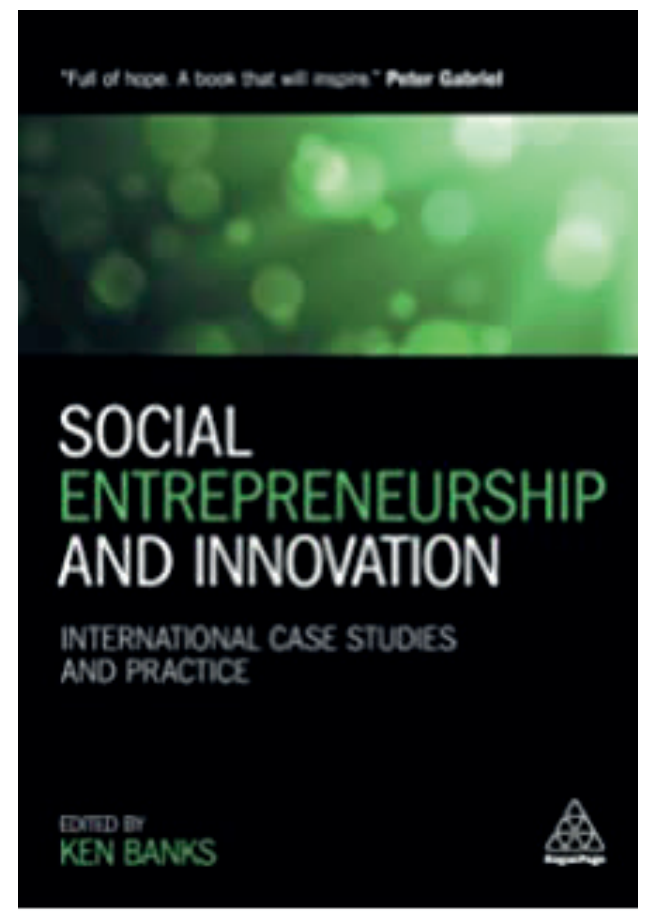

El libro se compone de trece capítulos, cada uno de los cuales relata el surgimiento de una innovación dentro de un contexto problemático, ya sea este en el campo político, económico, ambiental o de la salud ciudadana. La obra comienza con una magistral introducción hecha por el músico y productor británico Peter Gabriel, reconocido activista social en Europa y quien alguna vez fue vocalista de la famosa banda de pop, Génesis, y posteriormente solista afamado mundialmente por su tema "Slegdehammer" (1988). Gabriel fue ganador al precio de mejor canción escrita para una película con el tema "Down to Earth" de la película WALL.E (2008)

El libro compila las experiencias de emprendedores y sus historias de innovación social en países que no conocemos en la mayoría de los casos. Entre ellas podemos citar "Wonders of the Solar System", (Maravillas del Sistema
Solar) de Laura Stachel, obstetra estadounidense que, al hacer un viaje a Nigeria para trabajar de voluntaria en un hospital, decide quedarse por más tiempo para tratar de encontrar una solución a la alta tasa de mortalidad de mujeres en las salas de parto y debido a los frecuentes apagones de electricidad que impedían realizar las labores de parto cuando estos sucedían durante la noche.

Rodrigo Baggio, en "Closing Latin America's Digital divide" (Cerrando la brecha digital en América Latina) nos cuenta la historia de cómo él, con absoluta pasión por un mejor mañana para los más pobres, pudo transformar positivamente la vida de niños, jóvenes y adultos de favelas de Río de Janeiro dándoles los medios tecnológicos, Internet y computadoras, para incentivar en ellos un sentido de ciudadanía, acceso a la educación y empleo. Eso pese a la incredulidad de muchos.

Por su parte en "Data Science, Technology and Design for Social Justice" (Ciencia de datos, tecnología y diseño para la justicia social) de la periodista y comunicadora social Joumana al Jabri, nos relata sus motivos, las vicisitudes y finalmente los logros para fortalecer la libertad de expresión y la innovación en los territorios palestinos y el Líbano mediante el uso de Internet. Eso le acarreó problemas de censura, problemas políticos en incluso con la justicia israelí. 
Pese al pluralismo de las disciplinas del saber representada en cada uno de los casos y la diversidad de los emprendimientos innovadores a lo largo del libro, en todos ellos se deja distinguir un hilo conductor de la innovación social, la creencia compartida en una visión a futuro y el sentido de altruismo, tres aspectos que a fin de cuentas impulsan a estos innovadores para dar su mayor esfuerzo. Esfuerzo que va mucho más allá de la tarea de persuadir a individuos, comunidades o gobiernos para adoptar un producto o un proceso simplemente por ser lo último o más "novedoso" en el mercado. La enseñanza suprema de la obra es que todos podemos ser innovadores y todos podemos realmente aprender de todos, en cualquier lugar. El libro es una absoluta inspiración para todos aquellos que estén interesados en hacer la diferencia en la sociedad. 